\title{
Coupling Activation of Pro-Apoptotic Caspases With Autophagy in the Meckel's Cartilage
}

\author{
P. BÍLIKOVÁ ${ }^{1}$, E. ŠVANDOVÁ ${ }^{1}$, B. VESELÁ ${ }^{1}$, J. DOUBEK $^{1}$, A. POLIARD ${ }^{2}$, \\ E. MATALOVÁ ${ }^{1}$
}

${ }^{1}$ Department of Physiology, University of Veterinary and Pharmaceutical Sciences, Brno, Czech Republic, ${ }^{2}$ Laboratory of Orofacial Pathologies, Imaging and Biotherapies, Université Paris Descartes, France

Received May 25, 2018

Accepted July 26, 2018

Epub Ahead of Print October 23, 2018

\begin{abstract}
Summary
Mammalian Meckel's cartilage is a temporary structure associated with mandible development. Notably, its elimination is not executed by apoptosis, and autophagy was suggested as the major mechanism. Simultaneous reports point to pro-apoptotic caspases as novel participants in autophagic pathways in general. The aim of this research was to find out whether activation of pro-apoptotic caspases $(-2,-3,-6,-7,-8$ and -9) was associated with autophagy of the Meckel's cartilage chondrocytes. Active caspases were examined in serial histological sections of mouse mandible using immunodetection and were correlated with incidence of autophagy based on Beclin-1 expression. Caspase-2 and caspase- 8 were found in Beclin- 1 positive regions, whereas caspase- $3,-6,-7$ and -9 were not present. Caspase- 8 was further correlated with Fas/FasL and HIF-1a, potential triggers for its activation. Some Fas and FasL positivity was observed in the chondrocytes but caspase- 8 activation was found also in FasL deficient cartilage. HIF-1a was abundantly present in the hypertrophic chondrocytes. Taken together, caspase- 8 activation in the Meckel's cartilage was demonstrated for the first time. Caspase- 8 and caspase- 2 were the only pro-apoptotic caspases detected in the Beclin-1 positive segment of the cartilage. Activation of caspase- 8 appears FasL/Fas independent but may be switched on by HIF-1a.
\end{abstract}

\section{Key words}

Cartilage • Apoptosis • Autophagy • Caspase-2 • Caspase-8

\section{Corresponding author}

E. Matalová, Department of Physiology, University of Veterinary and Pharmaceutical Sciences, Palackého 1946/1, 61242 Brno, Czech Republic. E-mail: matalova@iach.cz

\section{Introduction}

Mammalian Meckel's cartilage (MC) is a temporary structure connected with proper mandible development and can be anatomically divided into three basic segments endowed with different fate (Amano et al. 2010). The anterior (distal) part contributes to formation of the mandibular symphysis, the posterior (proximal) provides a basis for formation of the malleus whereas the middle (intermediate) part becomes gradually degraded along with progressing ossification of the mandibular bone (Ishizeki et al. 1999, Parada and Chai 2015). In the mouse (the most common mammalian model), the onset of elimination corresponds with the prenatal day 15 (Sakakura et al. 2007, Yang et al. 2012) (Fig. 1A, B). At this stage, chondrocytes of the middle segment become hypertrophic and committed to terminal differentiation along with a progressive degradation of the extracellular matrix (Sakakura et al. 2007). The middle segment of the cartilage disappears at the prenatal day 18, starting from the region related to the first molar tooth germ (Sakakura et al. 2007, Ishizeki et al. 1999, Parada and Chai 2015).

The major mechanism involved in eliminating the middle MC segment was considered apoptosis (Shimada et al. 2003), the common mode of physiological programmed cell death. This was supported by studies showing increasing trend in $\mathrm{p} 53$ expression during MC degradation 
(Trichilis and Wroblewski 1997). However, no typical apoptotic features were found in chondrocytes within the degrading MC (Harada and Ishizeki 1998). Recently, autophagy was suggested as an alternative pathway of cell death based on the strong expression of Beclin-1 and $\mathrm{LC} 3 \mathrm{~b}$, the major autophagic proteins, in the cells committed to elimination (Yang et al. 2012).
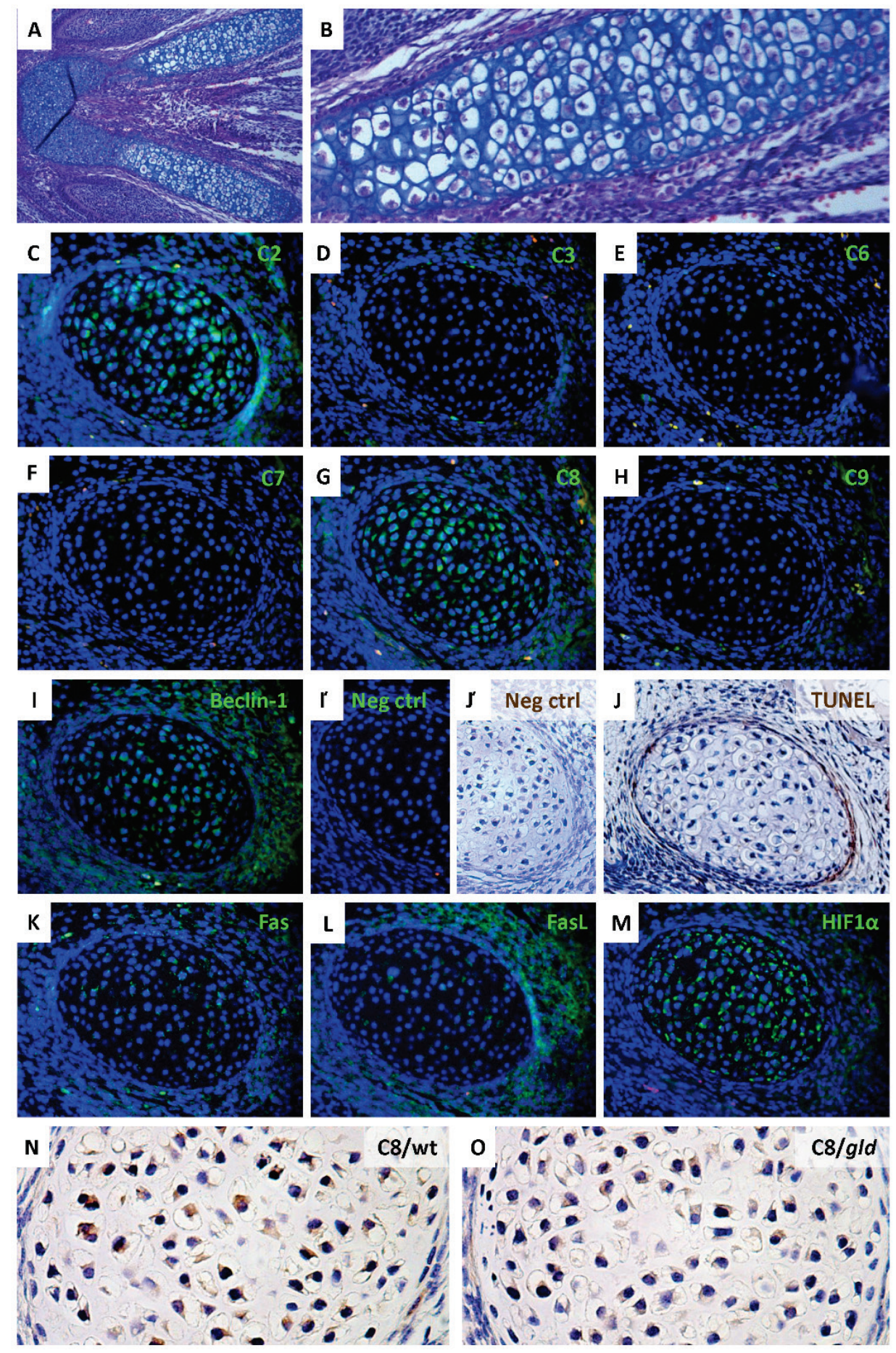

Fig. 1. Detection of pro- apoptotic and autophagic markers in histological sections of the middle part of the Meckel's cartilage. (A) Bilateral mouse Meckel's cartilages (transversal section) at the prenatal day 15, (B) detail of the middle part of the Meckel's cartilage formed by hypertrophic chondrocytes. (C-H) Active caspases in frontal sections at the prenatal day 15: (C) caspase-2, (D) caspase-3, (E) caspase-6, (F) caspase-7, (G) caspase-8, (H) caspase-9. (I-J) Cell death in the middle part of the Meckel's cartilage, longitudinal sections: (I) autophagy/Beclin-1, (J) apoptosis/TUNEL labeling. (K) Fas, (L) FasL and (M) HIF-1a, (N) active caspase-8 in wild type and (O) FasL knock-out ( $g / d$ ) Meckel's cartilage at the prenatal day 15. (A, B) haematoxylin-eosin and Alcian blue staining, (C-I, K-M) immunofluorescence, positive cells in green, DAPI counterstain in blue, (I') negative control for immunofluorescence, (J, N, O) immunohistochemistry, positive cells in brown, haematoxylin counterstain in blue, $\left(\mathrm{J}^{\prime}\right)$ negative control for immunohistochemistry. 
Independently and in parallel to these investigations, molecular cross-talks between apoptosis and autophagy have been gradually discovered (Eisenberg-Lerner et al. 2009) and pro-apoptotic caspases suggested as novel important regulators (Tsapras and Nezis 2017). Pro-apoptotic caspases are cysteineproteases activated in cascades and triggered either by ligand-receptor binding or via the intrinsic pathway initiated from mitochondria or endoplasmic reticulum. Caspase- 8 and caspase- 9 are considered as the initiator caspases, while caspases-3, -6 and -7 are an executive trio and caspase-2 has yet an unclear position (Shalini et al. 2015).

So far, caspase- 2 was reported in the $\mathrm{MC}$ in frame of a general study showing presence of this caspase during the course of cephalic development (Vanmuylder et al. 2015). Caspase-3 was specifically detected in the $\mathrm{MC}$, but only in perichondrium, and was related to apoptotic cells (Yang et al. 2012). Investigation of other pro-apoptotic caspases or their possible association with autophagy in the MC has not yet been performed.

The aim of this research was to investigate activation of pro-apoptotic caspases (caspase-2, -3, -6, -7, $-8,-9)$ in the hypertrophic chondrocytes within the middle segment of the Meckel's cartilage undergoing degradation to find out for possible temporospatial correlations with autophagic cell death.

Histological sections of mouse heads were used to detect active caspases in the $\mathrm{MC}$ at the stages corresponding to the onset of autophagy in the middle segment (Yang et al. 2012). In these sections, immunofluorescence (IF) and immunohistochemistry (IHC) based on application of specific primary antibodies allowing for detection of the active forms were exploited (caspase-2/PA5-39872 Thermo Fisher Scientific; caspase-3/9664, cleaved caspase-6/9761, caspase-7/9491, caspase-8/8592, caspase-9/9509, all from Cell Signaling; IHC and IF protocols in Svandova et al. 2014, Svandova et al. 2018).

The screening at the onset of degradation process (prenatal day 15) indicated that caspase-2 (Fig. 1C) and caspase-8 (Fig. 1G) were abundantly activated in the middle segment of the cartilage, whereas caspase-3, -6, -7 and -9 were not present (Fig. 1D, E, F, $\mathrm{H})$. The majority of hypertrophic chondrocytes at this stage was Beclin-1 positive (Fig. 1I) and TUNEL negative (Fig. 1J) in agreement with earlier published data (Yang et al. 2012). The same pattern of caspase-2 and -8 activation was observed the following two days (prenatal day 16 and 17) (data not shown) when the autophagic degradation peaks and Beclin-1 expression is followed by appearance of LC3b (Yang et al. 2012).

The co-activation of caspase- 2 and caspase- 8 suggests their possible interactions as already reported in other systems. Both caspases were indeed described to act via t-Bid (Lin et al. 2004, Fava et al. 2012). Additionally, caspase- 2 can be a substrate of caspase- 8 (van de Craen et al. 1999, Fava et al. 2012). However, caspase-8 has a general potential to activate all executive pro-apoptotic caspases whereas caspase-2 does not cleave executors (Forsberg et al. 2017). As no processing of executors $(3,6,7)$ was observed in the hypertrophic chondrocytes within the degrading part of the cartilage, caspase- 8 may act on other targets including caspase-2. To further explore this association in vivo is presently hindered by the caspase- 8 knock-out mice lethality before MC degradation (Varfolomeev et al. 1998).

Regarding autophagy, pro-apoptotic caspases including caspase- 2 and caspase- 8 are considered to have regulatory effects (Tsapras and Nezis 2017) although the data are mostly based on in vitro experiments with cancer cells. So far, caspase-2 was reported as involved in the control of mitochondrial levels of reactive oxygen species by preventing their accumulation (Tiwari et al. 2011). More specifically, caspase- 8 was demonstrated as able to cleave the autophagic proteins ATG3, ATG5 and Beclin-1 as well as RIPK1, which augments autophagy (Laussmann et al. 2011, He et al. 2012) and to modulate autophagy via interaction with p62 (Huang et al. 2013, Pan et al. 2013). Caspase-8 was also shown engaged in autophagy regulation by the FADD adapter (Young et al. 2012) which is associated with FasL/Fas signaling, the most common trigger of caspase- 8 mediated apoptosis (Strasser et al. 2009).

Fas/FasL expression has been previously investigated in the early stages of human mandible development, however prior to MC degradation (Hatakeyama et al. 2000). Therefore, additional analysis of Fas and FasL expression in the middle segment of the cartilage during the degradation process was performed. Serial histological sections of the MC and immunofluorescence (FasL sc-835, Fas sc-1024, both from Santa Cruz Biotechnology; protocol in Svandova et al. 2017) were used for this purpose. Fas and FasL expression was observed in the chondrocytes within the Beclin-1 positive segment of the MC (Fig. 1K, L). To find out if the FasL/Fas system could be engaged in caspase- 8 activation, the Meckel's cartilage in FasL deficient ( $g l d$ ) 
mice was investigated. Samples of gld mice were available from a previous study (Svandova et al. 2017). Based on immunohistochemistry, caspase- 8 activation was demonstrated also in the gld MC (Fig. 1N, O).

As another candidate activating caspase- 8 in the MC chondrocytes can be considered HIF-1 $\alpha$ (hypoxia inducible factor 1, alpha subunit). Activation of caspase- 8 via HIF-1 $\alpha$ was shown earlier in the growth plate chondrocytes in vivo and in rib cartilage derived cells in vitro (Bohensky et al. 2007). In these cells, decreased Beclin-1 expression and loss of caspase- 8 was demonstrated after HIF silencing. Despite growth plate and degrading MC chondrocytes differ, e.g. possible osteogenic fate of growth plate chondrocytes has been demonstrated recently (Yang et al. 2014, Jing et al. 2016), HIF-1 $\alpha$ expression was reported in both systems (Sakakura et al. 2008). To find out if temporospatial correlations can apply for HIF- $1 \alpha$, caspase- 8 and autophagy in the hypertrophic chondrocytes of the degrading middle segment of the $\mathrm{MC}$, immunofluorescence of HIF-1 (NB100-479SS, Novus Biologicals, citrate pre-treatment/10 min, 1:50/ON/4 ${ }^{\circ} \mathrm{C}$ ) was performed. Notably, HIF-1 $\alpha$ was abundantly expressed (Fig. 1M) in the caspase-2, caspase- 8 and Beclin-1 positive segment. Since HIF-1 $\alpha$ is a master regulator of homeostatic response to hypoxia, the HIF-1 $\alpha$ knock-out is lethal prior to development of the MC (Iyer et al. 1998) and therefore cannot be analyzed to determine the impact on caspase activation and autophagy within the $\mathrm{MC}$ in vivo. In summary, we reported for the first time presence of active caspase- 8 in the MC. Based on our temporospatial analysis, caspase-2 and caspase- 8 are activated in non-apoptotic and Beclin-1 positive regions within the degrading part of the Meckel's cartilage. The co-localization of these caspases with Beclin-1 suggests their possible involvement in the chondrocyte autophagic cell death. Additionally, activation of these caspases appears FasL/Fas independent but may be triggered by HIF-1 $\alpha$.

\section{Conflict of Interest}

There is no conflict of interest.

\section{Acknowledgements}

This research was supported by the Grant Agency of the Czech Republic (16-18430S).

\section{References}

AMANO O, DOI T, YAMADA T, SASAKI A, SAKIYAMA K, KANEGAE H, KINDAICHI K: Meckel's cartilage: discovery, embryology and evolution: overview of the specificity of Meckel's Cartilage. J Oral Biosci 52: $125-135,2010$.

BOHENSKY J, SHAPIRO IM, LESHINSKY S, TERKHORN SP, ADAMS CS, SRINIVAS V: HIF-1 regulation of chondrocyte apoptosis: induction of the autophagic pathway. Autophagy 3: 207-214, 2007.

EISENBERG-LERNER A, BIALIK S, SIMON HU, KIMCHI A: Life and death partners: apoptosis, autophagy and the cross-talk between them. Cell Death Differ 16: 966-975, 2009.

FAVA LL, BOCK FJ, GELEY S, VILLUNGER A: Caspase-2 at a glance. J Cell Sci 125: 5911-5915, 2012.

FOSBERG J, ZHIVOTOVSKY B, OLSSON M: Caspase-2: an orphan enzyme out of the shadows. Oncogene 36: 5441-5444, 2017.

HARADA Y, ISHIZEKI K: Evidence for transformation of chondrocytes and site-specific resorption during the degradation of Meckel's cartilage. Anat Embryol 197: 439-450, 1998.

HATAKEYAMA S, TOMICHI N, OHARA-NEMOTO Y, SATOH M: The immunohistochemical localization of Fas and Fas ligand in jaw bone and tooth germ of human foetuses. Calcif Tissue Int 66: 330-337, 2000.

HE W, WANG Q, XU J, XU X, PADILlA MT, REN G, GOU X, LI Y: Attenuation of TNFSF10/TRAIL-induced apoptosis by an autophagic survival pathway involving TRAF2-and RIPK1/RIP1-mediated MAPK8/JNK activation. Autophagy 8: 1811-1821, 2012.

HUANG S, OKAMOTO K, YU C, SINICROPE FA: p62/sequestosome-1 up-regulation promotes ABT-263-induced caspase-8 aggregation/activation on the autophagosome. J Biol Chem 288: 33654-33666, 2013.

JING Y, HINTON RJ, CHAN KS, FENG JQ: Co-localization of cell lineage markers and the tomato signal. $J$ Vis Exp 118: e54982, 2016. 
ISHIZEKI K, SAITO H, SHINAGAWA T, FUJIWARA N, NAWA T: Histochemical and immunohistochemical analysis of the mechanism of calcification of Meckel's cartilage during mandible development in rodents. J Anat 194: 265-277, 1999.

IYER NV, KOTCH LE, AGANI F, LEUNG SW, LAUGHNER E, WENGER RH, GASSMANN M, GEARHART JD, LAWLER AM, YU AY, SEMENZA GL: Cellular and developmental control of O2 homeostasis by hypoxiainducible factor 1 alpha. Genes Dev 12: 149-162, 1998.

LAUSSMANN MA, PASSANTE E, DÜSSMANN H, RAUEN JA, WÜRSTLE ML, DELGADO ME, DEVOCELLE M, PREHN JH, REHM M: Proteasome inhibition can induce an autophagy-dependent apical activation of caspase-8. Cell Death Differ 18: 1584-1597, 2011.

LIN CF, CHEN CL, CHANG WT, JAN MS, HSU LJ, WU RH, TANG MJ, CHANG WC, LIN YS: Sequential caspase2 and caspase-8 activation upstream of mitochondria during ceramide and etoposide-induced apoptosis. J Biol Chem 279: 40755-40761, 2004.

PAN JA, FAN Y, GANDHIRAJAN RK, MADESH M, ZONG WX: Hyperactivation of the mammalian degenerin MDEG promotes caspase-8 activation and apoptosis. J Biol Chem 288: 2952-2963, 2013.

PARADA C, CHAI Y: Mandible and tongue development. Curr Top Dev Biol 115: 31-58, 2015.

SAKAKURA Y, HOSOKAWA Y, TSURUGA E, IRIE K, NAKAMURA M, YAJIMA T: Contributions of matrix metalloproteinases toward Meckel's cartilage resorption in mice: immunohistochemical studies, including comparisons with developing endochondral bones. Cell Tissue Res 328: 137-151, 2007.

SAKAKURA Y, SHIBUIT, IRIE K, YAJIMA T: Metabolic mode peculiar to Meckel's cartilage: immunohistochemical comparisons of hypoxia-inducible factor-1alpha and glucose transporters in developing endochondral bones in mice. Eur J Oral Sci 116: 341-352, 2008.

SHALINI S, DORSTYN L, DAWAR S, KUMAR S: Old, new and emerging functions of caspases. Cell Death Differ 22: 526-539, 2015.

SHIMADA M, YAMAMOTO M, WAKAYAMA T, ISEKI S, AMANO O: Different expression of 25-kDa heat-shock protein (Hsp25) in Meckel's cartilage compared with other cartilages in the mouse. Anat Embryol 206: 163-173, 2003.

STRASSER A, JOST PJ, NAGATA S: The many roles of FAS receptor signaling in the immune system. Immunity 30: 180-192, 2009.

SVANDOVA E, LESOT H, VANDEN BERGHE T, TUCKER AS, SHARPE PT, VANDENABEELE P, MATALOVA E: Non-apoptotic functions of caspase-7 during osteogenesis. Cell Death Dis 5: e1366, 2014.

SVANDOVA E, VESELA B, LESOT H, POLIARD A, MATALOVA E: Expression of Fas, FasL, caspase-8 and other factors of the extrinsic apoptotic pathway during the onset of interdigital tissue elimination. Histochem Cell Biol 147: 497-510, 2017.

SVANDOVA E, VESELA B, TUCKER AS, MATALOVA E: Activation of pro-apoptotic caspases in non-apoptotic cells during odontogenesis and related osteogenesis. Front Physiol 9: 174, 2018.

TIWARI M, LOPEZ-CRUZAN M, MORGAN WW, HERMAN B: Loss of caspase-2-dependent apoptosis induces autophagy after mitochondrial oxidative stress in primary cultures of young adult cortical neurons. $J$ Biol Chem 286: 8493-8506, 2011.

TSAPRAS P, NEZIS IP: Caspase involvement in autophagy. Cell Death Differ 24: 1369-1379, 2017.

TRICHILIS A, WROBLEWSKI J: Expression of p53 and hsp70 in relation to apoptosis during Meckel's cartilage development in the mouse. Anat Embryol 196: 107-113, 1997.

VAN DE CRAEN M, DECLERCQ W, VAN DEN BRANDE I, FIERS W, VANDENABEELE P: The proteolytic procaspase activation network: an in vitro analysis. Cell Death Differ 6: 1117-1124, 1999.

VANMUYLDER N, LEJONG M, CHOA-DUTERRE M, LOURYAN S: Caspase-2 immunohistochemistry in differentiating cells during mouse cephalic development. Eur J Anat 19: 189-195, 2015.

VARFOLOMEEV EE, SCHUCHMANN M, LURIA V, CHIANNIKULCHAI N, BECKMANN JS, METT IL, REBRIKOV D, BRODIANSKI VM, KEMPER OC, KOLLET O, LAPIDOT T, SOFFER D, SOBE T, AVRAHAM KB, GONCHAROV T, HOLTMANN H, LONAI P, WALLACH D: Targeted disruption of the mouse caspase 8 gene ablates cell death induction by the TNF receptors, Fas/Apo1, and DR3 and is lethal prenatally. Immunity 9: 267-276, 1998. 
YANG G, ZHU L, HOU N, LAN Y, WU XM, ZHOU B, TENG Y, YANG X: Osteogenic fate of hypertrophic chondrocytes. Cell Res 24: 1266-1269, 2014.

YANG RT, ZHANG C, LIU Y, ZHOU HH, LI ZB: Autophagy prior to chondrocyte cell death during the degeneration of Meckel's cartilage. Anat Rec 295: 734-741, 2012.

YOUNG MM, TAKAHASHI Y, KHNA O, PARK S, HORI T, YUN J, SHARMA AK, AMIN S, HU CD, ZHANG J, KESTER M, WANG HG: Autophagosomal membrane serves as platform for intracellular death-inducing signaling complex (iDISC)-mediated caspase-8 activation and apoptosis. J Biol Chem 287: 12455-12468, 2012. 